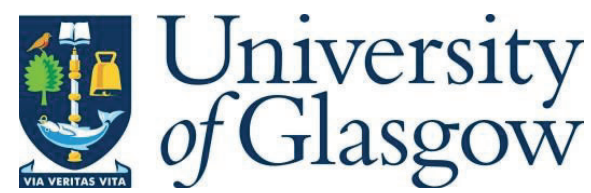

Kim, Y., Rahardjo, H. and Tsen-Tieng, D. L. (2021) Mechanical behavior of trees with structural defects under lateral load: a numerical modeling approach.

Urban Forestry and Urban Greening, 59, 126987. (doi: 10.1016/j.ufug.2021.126987)

There may be differences between this version and the published version. You are advised to consult the publisher's version if you wish to cite from it.

http:/eprints.gla.ac.uk/242470/

Deposited on: 26 May 2021

Enlighten - Research publications by members of the University of Glasgow http://eprints.gla.ac.uk 


\title{
Mechanical behavior of decayed trees under lateral load: a numerical modeling approach
}

\begin{abstract}
Tree structural defects are a common cause of tree failure. These structural defects often result from progressive wood decay over time. Therefore, special attention is required to study the changes in the lateral responses of trees as defects are introduced. This can show how, using these changes, significant tree defects that can ultimately disrupt tree stability be detected. In this study, a three-dimensional (3D) numerical model was proposed to investigate the mechanical behavior of trees with structural defects under lateral load. The 3D numerical model was verified by non-destructive tree pulling tests with the incorporation of the overall stiffness of the tested trees. Then, trees with structural defects were simulated with different tree geometries and defect sizes. In addition, to examine the effect of decay volume extents and deterioration in elastic modulus due to decay, a simplified two-dimensional (2D) numerical simulation was performed. Through comparison with the results of the tree pulling tests, the 3D numerical model was found to be appropriate and applicable for the evaluation of the tree's lateral response as well as the effects on tree stability. Numerical analysis results, therefore, confirmed the fact that the mechanical behavior of the tree under lateral load is strongly dependent on the presence of significant decay that can cause whole tree failure.
\end{abstract}

Keywords: Tree failure; Decay; Root plate; Failure chart; Numerical analysis

\section{Introduction}

Urban trees are a crucial component of the sustainable built environment and provide numerous benefits, but can cause damage to property, infrastructure, and injury or loss of life if they fail. There have been several classifications of tree failures that can be defined as the breaking of any branch, trunk, root, or the loss of mechanical support in the roots (Dunster et al. 2013). Factors influencing tree failures include soil conditions, tree health, species, branch attachment properties, condition of roots, presence of decay and weather conditions etc. Low soil strength causes instability of trees with root defects (Rahardjo et al., 2014). Structural instabilities and lack of root components cause tree failure (Miesbauer et al., 2014; Lee, 2016). The presence of decay in a trunk and root has a significant effect on the mechanical behavior of the tree, which can lead to tree failure (Kane et al. 2001; Lonsdale 2007; Smiley 2008, Kim et al., 2020). Climatic and environmental conditions affect tree growth and tree stability (Rahardjo et al., 2009; Khalilnejad et al., 2013; Harnas et al., 2015). 
Several studies have been undertaken to develop devices and procedures for the detection of the presence of decay (Wang and Allison, 2008; Johnstone et al., 2010; Arciniegas et al., 2014), to measure the strength of tree components (e.g., bending moments) (Kane and Clouston, 2008), to model wind load dynamics (James et al., 2006; Li et al., 2018; Li et al., 2019), to perform an assessment of mechanical stability of root architecture (Smiley 2008; Bartens et al. 2010; Ow et al. 2010; Gilman et al. 2013; Lee, 2016), and to conduct tree pulling tests (Moore, 2000; Peltola et al., 2000; Koizumi et al., 2010; Ow et al., 2010; Kim et al., 2020).

The most common types of tree failures are tipping and fractures. These are mainly due to decayed roots and trunks, which cause breaking of trunks and roots (Teho, 2009). In this regard, existing researches concentrated either on the experimental assessments of decayed trees or the numerical simulations of sound trees. However, there has not been any study carried out on the development of a numerical model for assessing decayed trees. Information on the lateral responses of decayed trees is usually collected from field experiments and measurements, which are costly, resource-intensive, and time-consuming. On the other hand, a more comprehensive investigation of the response of decayed trees under various conditions can be carried out using numerical modelling.

The objective of this study is to present a three-dimensional (3D) numerical model to simulate decayed trees subjected to lateral load. After verification of the numerical model against the results of the tree pulling tests, the mechanical behavior of both sound and decayed trees was investigated in terms of lateral deflections, equivalent stresses, and failure charts. In addition, the effects of decay's volume and deterioration elastic modulus on the mechanical behavior of decayed trees were discussed by conducting simplified two-dimensional (2D) numerical simulations.

\section{Methodology}

\subsection{Numerical modeling of the tree pulling test}

A full-scale non-destructive tree pulling test (Fig. 1) performed by Kim et al., (2020) was used to validate the numerical modeling technique in predicting a tree's lateral response and deformation. The tree pulling tests were performed on the three species (i.e., Khaya senegalensis, Syzygium grande, and Samana saman). Total six trees were pulled using a winch that was placed on an anchor tree. A pulling block was positioned on a tested tree at an accessible height from the ground surface. A load cell was connected to the winch as well as 
the pulling block by a double-rope pulley system. A displacement-controlled test with a constant increment of $5 \mathrm{~cm}$ was carried out to record the corresponding resistance force. The angle $\alpha$ between the pulling rope and the ground surface was determined as $\tan ^{-1}\left[\left(H_{P}-\right.\right.$ $\left.\left.H_{W}\right) / L_{T}\right]$, where $L_{T}$ is the distance between the anchor tree and the tested tree; $H_{P}$ and $H_{W}$ are the height of the pulling block and the winch, respectively.

The two species, i.e. Khaya senegalensis and Samana saman were simulated using ANSYS version17.2 (ANSYS, 2011). They tend to develop a shallow root system because of the high annual precipitation (Chow and Roth, 2006), which is named as the root-soil plate (Coutts, 1983; Elie and Ruel, 2005). Therefore, a three-dimensional (3D) numerical model (Fig. 2) was created with a root plate characterized by the diameter $B$ and the thickness $\beta B$ and with a trunk characterized by the diameter $n B$ and the height $m B$, where $\beta, n, m$ are the dimensionless geometry parameters. The parameters $D_{G}$ and $D_{B}$ are the trunk diameter at the ground surface and the block height, respectively. Table 1 summarize morphometric data of the simulated trees.

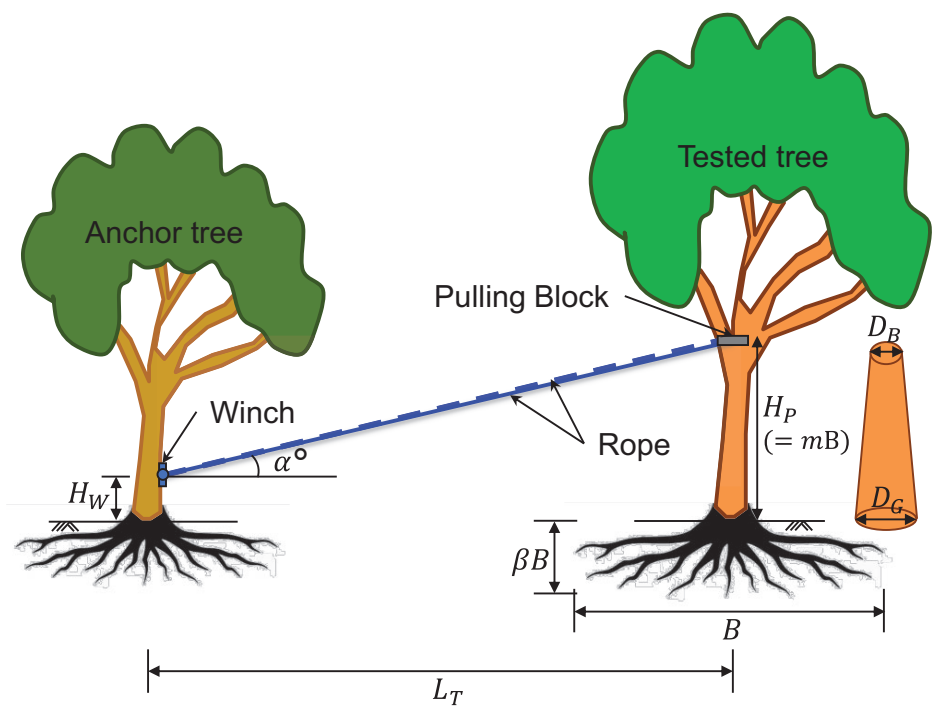

Fig. 1. Schematic diagram of tree pulling tests performed by Kim et al. (2020).

Table 1 Morphometric data for tested trees.

\begin{tabular}{llllll}
\hline & $\begin{array}{l}\text { Diameter at the } \\
\text { ground surface, } \\
D_{G}(\mathrm{~m})\end{array}$ & $\begin{array}{l}\text { Diameter at the } \\
\text { block height, } \\
D_{B}(\mathrm{~m})\end{array}$ & $\begin{array}{l}\text { Tapered ratio, } \\
T_{r}=D_{G} / D_{B}\end{array}$ & $\begin{array}{l}\text { Block height, } \\
H_{p}(=m B) \\
(\mathrm{m})\end{array}$ & $\begin{array}{l}\text { Second moment } \\
\text { of inertia, } I \\
\left(\mathrm{~m}^{4}\right)\end{array}$ \\
\hline $\begin{array}{l}\text { Khaya } \\
\text { senegalensis }\end{array}$ & 0.54 & 0.29 & 1.85 & 9.28 & $3.61 \mathrm{E}-4$ \\
$\begin{array}{l}\text { Samanea } \\
\text { saman }\end{array}$ & 0.45 & 0.26 & 1.71 & 9.80 & $2.28 \mathrm{E}-4$ \\
\hline
\end{tabular}




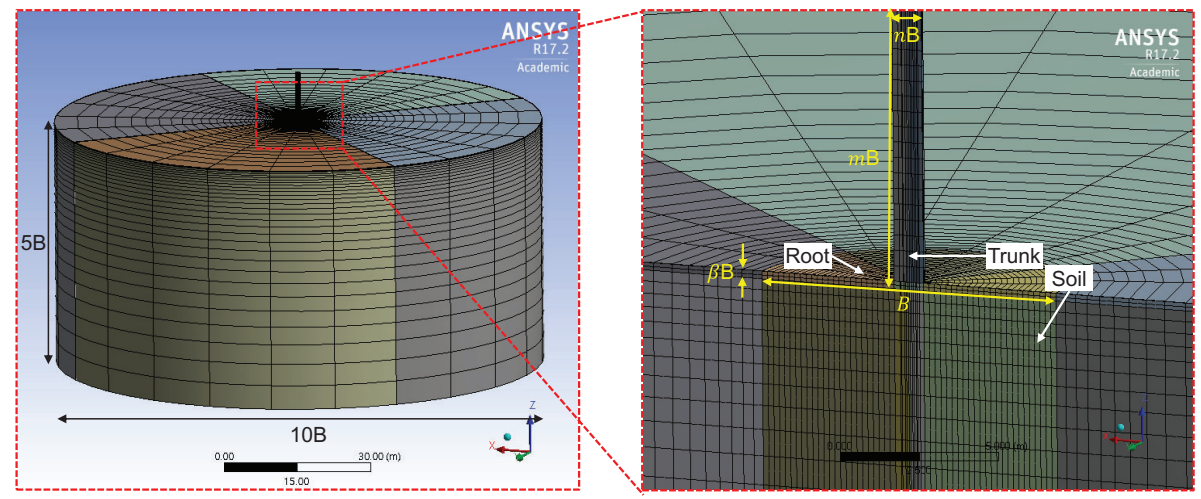

Fig. 2. Numerical model for the tree pulling test.

The radial boundaries of the mesh comprise a width of 5 times the root diameter $B$ from the trunk center, and the base boundary of the mesh was positioned $5 B$ beneath the root plate. These dimensions were considered adequate to avoid the influence of boundary effects on the lateral response of the tree. The outer boundary of the mesh was fixed against displacements. The geometries of the trunk, root plate, and soil were modeled with finite elements and a finer mesh less than $0.2 \mathrm{~m}$ was created in the region adjacent to the trunk and root plate, allowing for a rigorous treatment of soil-root plate interaction. The interface boundary condition between the root plate and the soil was treated as a no-separation model that allows a movement of the root plate relative to the soil element, which permits unlimited tensile normal stresses and prevents full separations.

The trunk and root plate were considered as a non-porous and linear-elastic material at all times. In contrast, the soil underneath the root plate was prescribed by an isotropic and elasto-plastic constitutive law using the Mohr-Coulomb failure criterion with an associated flow rule. The elastic behavior of the tree was inferred from the tree pulling test by estimating the overall stiffness of the tree. Derivations of the experimental overall stiffness using load test data assumed that the tree is a tapered shape in a state of plane stress. The lateral displacement at the point of the attachment could be approximated by incorporating the tapered ratio of the trunk diameters at the bottom and the top. The overall stiffness of the tested tree $\left(E_{\text {tree }}\right)$ can be calculated as (Soltis, 1999):

$E_{\text {tree }}=\frac{P H_{p}^{3}}{3 I \delta} \times T_{r}^{3}$

where $P$ is lateral force acting on the block, $H_{p}$ is the height of the tree at the block, $\delta$ is the displacement of the tree at the point of the block, $I$ is the second moment of inertia, and 
$T_{r}$ is the tapered ratio. To consider the actual root architecture, the equivalent elastic modulus of the root plate was calculated with respect to the volume of the root and soil, which is given by (Kim et al., 2020):

$E_{\text {eq }}=\frac{E_{\text {root }} V_{\text {root }}+E_{\text {soil }} V_{\text {soil }}}{V_{\text {root }}+V_{\text {soil }}}$

where $E_{e q}$ is the equivalent elastic modulus; $E_{\text {root }}$ and $E_{\text {soil }}$ are the elastic modulus of root and soil, respectively; $V_{\text {root }}$ and $V_{\text {soil }}$ are the volume of root and soil, respectively. The soil stiffness was homogenous with elastic modulus that depends on the matric suction level (Rahardjo et al., 2011; Khalilnejad et al., 2013). To consider the field condition, a matric suction of $5 \mathrm{kPa}$ as measured from the tensiometers that were installed at the time of the tree pulling test was used to determine elastic modulus of the soil using the Rahardjo equation (Rahardjo et al., 2011). Since their laboratory direct shear tests and numerical analyses incorporated a compacted residual soil of Singapore, the Rahardjo's equation is also applicable to the residual soil at the test site. An unsaturated triaxial test under a consolidated drained condition was carried out to determine the drained shear strength of the soil. Material properties of the soil and the tree used in the numerical simulation are summarized in Tables 2 and 3, respectively.

Table 2 Soil properties used in the numerical simulation.

\begin{tabular}{|c|c|c|c|c|c|c|}
\hline & \multicolumn{6}{|c|}{ Material properties } \\
\hline & $\begin{array}{l}\text { Matric } \\
\text { suction } \\
(\mathrm{kPa})\end{array}$ & $\begin{array}{l}\text { Elastic } \\
\text { modulus, } \\
E_{\text {soil }}(\mathrm{kPa})\end{array}$ & $\begin{array}{l}\text { Poisson's } \\
\text { ratio, } v_{\text {soil }}\end{array}$ & $\begin{array}{l}\text { Effective } \\
\text { friction angle, } \\
\phi^{\prime} \text { (deg) }\end{array}$ & $\begin{array}{l}\text { Effective } \\
\text { cohesion, } c^{\prime} \\
(\mathrm{kPa})\end{array}$ & $\begin{array}{l}\text { Unit weight, } \\
\gamma_{t}(\mathrm{kN} / \mathrm{m} 3)\end{array}$ \\
\hline Unsaturated soil & 5 & 5000 & 0.35 & 30 & 10 & 18 \\
\hline
\end{tabular}

Table 3 Morphometric data and properties of tested trees used in the numerical simulation.

\begin{tabular}{llllllll}
\hline & $\begin{array}{l}\text { Root } \\
\text { depth, } \\
\beta B(\mathrm{~m})\end{array}$ & $\begin{array}{l}\text { Root } \\
\text { diameter, }\end{array}$ & $\begin{array}{l}\text { Trunk } \\
\text { diameter, } \\
n B(\mathrm{~m})\end{array}$ & $\begin{array}{l}\text { Trunk } \\
\text { height } \\
m B(\mathrm{~m})\end{array}$ & $\begin{array}{l}\text { Portion of } \\
\text { root volume } \\
(\%)\end{array}$ & $\begin{array}{l}\text { Overall } \\
\text { stiffness by } \\
\text { tree pulling } \\
\text { tests }(\mathrm{Pa})\end{array}$ & $\begin{array}{l}\text { Equivalent } \\
\text { elastic modulus } \\
E_{e q} \\
(\mathrm{kPa})\end{array}$ \\
\hline $\begin{array}{l}\text { Khaya } \\
\text { senegalensis }\end{array}$ & 0.6 & 8.0 & 0.47 & 9.28 & 30 & $7.50 \mathrm{E}+08$ & $3.07 \mathrm{E}+05$ \\
$\begin{array}{l}\text { Samanea } \\
\text { saman }\end{array}$ & 1.2 & 9.2 & 0.37 & 9.80 & 30 & $2.65 \mathrm{E}+09$ & $5.80 \mathrm{E}+05$ \\
\hline
\end{tabular}

\subsection{Three-dimensional (3D) numerical modeling of a decayed tree}

A concept of $t / R$ ratio was adopted in this study to model a decay developed in a trunk and root. The $t / R$ ratio is the ratio of the sound wood shell thickness $t$ to the radius of 
the cross-section $R$. Fig. 3 represents a cross-section of a trunk or root with a center column of decayed wood (dotted area). The $t$ is the outer shell of sound non-decayed wood. As an example, a $t / R$ ratio of $30 \%$ or 0.30 indicates that the internal wood decay has consumed $2 / 3$ of the cross-section.

Fig. 4 shows a general layout of the stability problem of a decayed tree used for the $3 \mathrm{D}$ numerical modeling. A decayed wood volume with a diameter $B^{\prime}$ and a thickness $\beta^{\prime} B^{\prime}$ is situated on the root plate, and a decayed wood volume with a diameter $n^{\prime} B^{\prime}$ and $2 \mathrm{~m}$ height is situated on the root and trunk. Fig. 5 shows a finite element mesh for the decayed tree system that has the $t / R$ ratio of 0.1 . The same elastic modulus for the trunk and root was assumed to be 3.0 GPa. A reduced elastic modulus was used for the decayed wood, which leads to a partial transfer of lateral loads to other tree members. This study emphasizes the effects of decay in the tree's response to lateral loads. The stiffness parameters of sound and decayed trees used in the numerical simulation are summarized in Table 4.

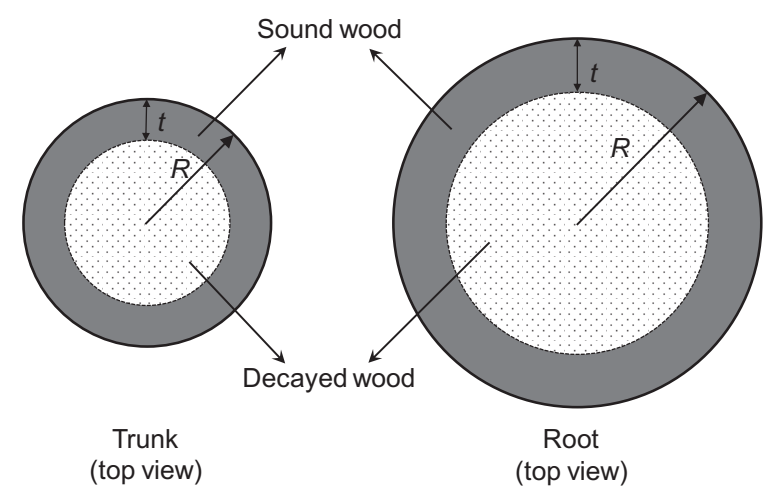

Fig. 3. The diagram of $t / R$ ratio for a center column of decayed wood.

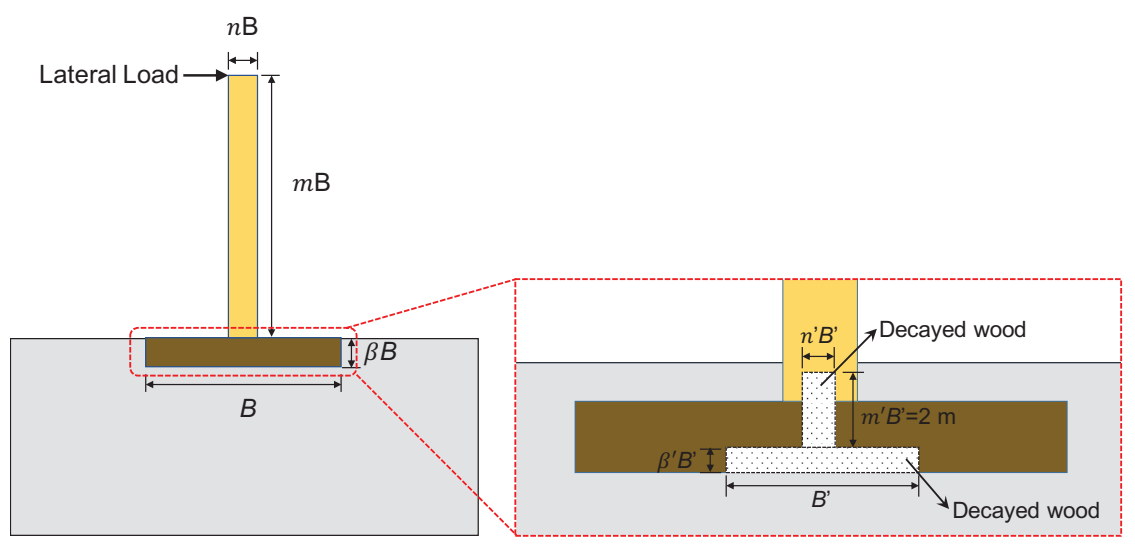

Fig. 4. Problem notation of a decayed tree in 3D modeling 


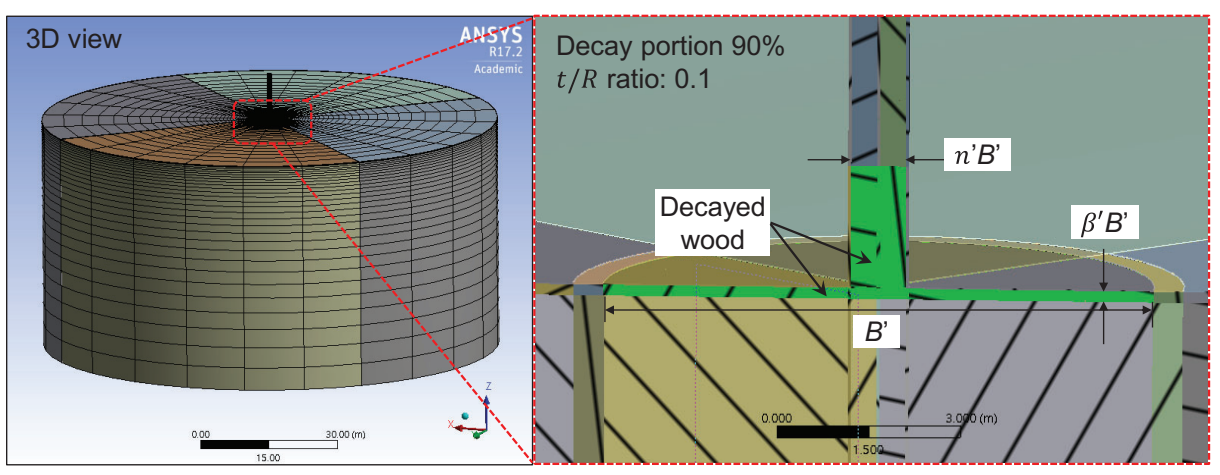

Fig. 5. Numerical model for a decayed tree in $3 \mathrm{D}$ modeling.

Table 4 Tree properties used for 3D decay modeling.

\begin{tabular}{lllll}
\hline & Material properties & & & \\
\cline { 2 - 5 } & Constitutive & Elastic modulus, & Poisson's ratio, & Unit weight, \\
& model & $E_{\text {tree }}(\mathrm{kPa})$ & $v_{\text {soil }}$ & $\gamma_{t}(\mathrm{kN} / \mathrm{m} 3)$ \\
\hline Trunk & Linear elastic & $3.00 \mathrm{E}+06$ & 0.30 & 10 \\
Root & Linear elastic & $3.00 \mathrm{E}+06$ & 0.30 & 10 \\
Decayed wood & Linear elastic & $3.00 \mathrm{E}+04$ & 0.30 & 10 \\
\hline
\end{tabular}

\subsection{Two-dimensional (2D) numerical modeling of a decayed tree}

In order to investigate the effects of volume and elastic modulus of the decayed wood on the lateral behavior of a tree, a 2D numerical model was created as shown in Fig. 6. A typical tree geometry was used and a triangle-shaped decayed wood with a width $D$ and a height $\kappa D$ is situated on the root plate as well as the trunk. This shape was chosen because wood decay fungi infection usually starts from roots and the extent of decay is usually highest at the base and reduces with increasing height of the trunk. The $\kappa$ ranged from 0.25 to 2.00 to represent the various volumes of the decayed wood. A reduced elastic modulus of the decayed wood was used by varying parameter $\omega$ that reduced the elastic modulus of the trunk and root. The material parameters and controlling parameters adopted for the 2D numerical modeling were summarized in Tables 5 and 6, respectively. 


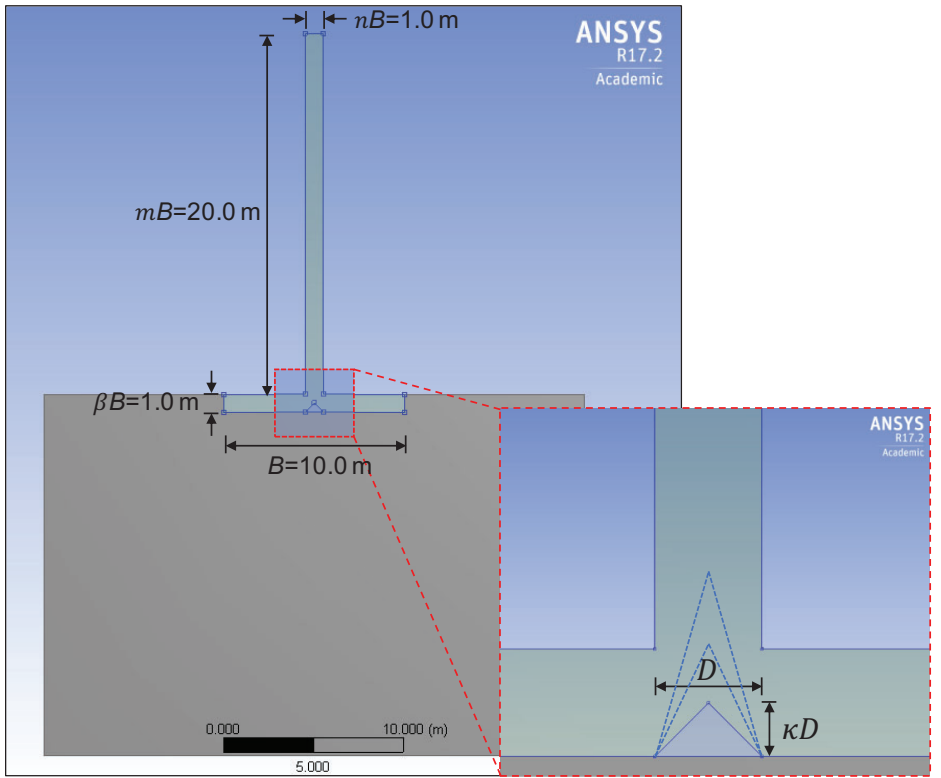

Fig. 6. Problem notation and numerical model for a decayed tree in 2D modeling.

Table 5 Soil properties used for 2D numerical modeling.

\begin{tabular}{lllllll}
\hline \multicolumn{7}{l}{ Material properties } \\
\cline { 2 - 7 } & $\begin{array}{l}\text { Matric } \\
\text { suction } \\
(\mathrm{kPa})\end{array}$ & $\begin{array}{l}\text { Elastic } \\
\text { modulus, } \\
E(\mathrm{kPa})\end{array}$ & $\begin{array}{l}\text { Poisson's } \\
\text { ratio, } v_{\text {soil }}\end{array}$ & $\begin{array}{l}\text { Effective } \\
\text { friction angle, } \\
\phi^{\prime}(\mathrm{deg})\end{array}$ & $\begin{array}{l}\text { Effective } \\
\text { cohesion, } c^{\prime} \\
(\mathrm{kPa})\end{array}$ & $\begin{array}{l}\text { Unit weight, } \\
\gamma_{t}(\mathrm{kN} / \mathrm{m} 3)\end{array}$ \\
\hline Unsaturated soil & 5 & 5000 & 0.35 & 30 & 10 & 18 \\
Trunk & - & $1.23 \mathrm{E}+06$ & 0.30 & - & - & 10 \\
Root & - & $1.23 \mathrm{E}+06$ & 0.30 & - & - & 10 \\
Decayed wood & - & $\omega \times E_{\text {Tree }}$ & 0.3 & - & - & 10 \\
\hline
\end{tabular}

Table 6 Range of parameters adopted for 2D numerical modeling.

\begin{tabular}{ll}
\hline Parameter & Value or Range \\
\hline Trunk height, $m B$ & $20 \mathrm{~m}$ \\
Root diameter, $B$ & $10 \mathrm{~m}$ \\
Trunk diameter, $n B$ & $1.0 \mathrm{~m}$ \\
Root thickness, $\beta B$ & $1.0 \mathrm{~m}$ \\
$\kappa$ & $0.25,0.50,0.75,1.0,1.25,1.5,1.75,2.0$ \\
$\omega$ & $0.001,0.005,0.01,0.05,0.1,0.5,1.0$ \\
Maximum lateral load & $60 \mathrm{kN}$ \\
\hline
\end{tabular}

\subsection{Failure criteria for materials}

Material failure can be characterized by any action to separate the material or to create new free surfaces depending on the geometrical scale (Boresi and Schmidt, 2002). The failure criteria of an engineering material are required so that material scientists and engineers can determine the cause of failures by describing the failure process and can suggest preventive 
measures of the failure from recurring. Material failures lead to structural failures that can be characterized by the loss of the designed structural function/integrity to sustain the load. The structural failure is frequently caused by the inability of the structural members, e.g., columns, beams, panel/plates, shells and others to support the loading.

There are two basic material groups: ductile materials and brittle materials. Ductile materials exhibit a large amount of strain before it fractures, whereas brittle materials only undergo small strains before fracture. The fracture strain is a measure of ductility. For a brittle material, there is usually no obvious yield stress and therefore, the fracture or rupture stress is much more important. The fracture of brittle materials is mostly due to tensile failure. The structural component that is made up of a brittle material is safe as long as the maximum normal stress is less than the ultimate strength of a tensile test specimen. For a typical ductile material, there often exists an obvious yield point, beyond which the deformation would be too large so that the material is no longer functional for serviceability. Failure is accompanied by excess deformation. Therefore, for ductile materials, the most important point is not the rupture or fracture stress but the yield stress. The yielding of ductile materials is mostly due to shear failure. The typical yield criteria used for ductile materials are the Tresca criterion (Tresca, 1864) and the von Mises criterion (von Mises, 1913).

In this study, the von Mises criterion was used to estimate the wooden material failure, such as trunk failures and/or root failures, which states that yielding occurs when the deviatoric strain energy density reaches a critical value. The structural component of interest yields when the distortion energy per unit volume $\left(u_{d}\right)$ is more or equal than that occurring in a tensile test specimen at yield $\left(u_{y}\right)$, i.e.,

$u_{d}>u_{y}$

$u_{y}=\frac{(1+v) \sigma_{y i e l d}^{2}}{3 E}$

where $v$ is the Poisson's ratio of a material, $E$ is the elastic modulus of a material, $\sigma_{y i e l d}$ is the yield stress on the stress-strain curve. The distortion energy per unit volume yields:

$u_{d}=\frac{(1+v)}{6 E}\left[\left(\sigma_{1}-\sigma_{2}\right)^{2}+\left(\sigma_{2}-\sigma_{3}\right)^{2}+\left(\sigma_{3}-\sigma_{1}\right)^{2}\right]$

where $\sigma$ is the stress. The criterion reduces to yielding to occur when, 
$\sqrt{\frac{1}{2}\left[\left(\sigma_{1}-\sigma_{2}\right)^{2}+\left(\sigma_{2}-\sigma_{3}\right)^{2}+\left(\sigma_{3}-\sigma_{1}\right)^{2}\right]} \geq \sigma_{\text {yield }}$

In Eq. (5), the term on the left is the von Mises stress or equivalent stress that is denoted by $\sigma_{e q}$ in ANSYS.

\section{Results and discussion}

\subsection{Comparison with field measurements}

The 3D numerical modeling technique was verified by comparing the measured and predicted results for the load-deflection curves. The validation focused on the elastic behaviors because the pulling tests were terminated when the tree deflection reached a maximum value of $60 \mathrm{~cm}$ for the safety of the trees employed in the tests. Fig. 7 shows comparisons between the predicted and the measured load-deflection curves for the two species. The pulling test results showed a bit stiffer lateral behavior than the predicted one. A reasonably good agreement of load-deflection relationships was observed between the numerical analysis results and pulling test results for both tree species. Both the pulling tests and numerical analyses indicated that the load-deflection relationships exhibited linear elastic behavior. As the lateral load increased, the lateral deflection also increased proportionally. Overall, the numerical model of the trunk-root plate-soil system with the incorporation of the tree strength was an appropriate approach that is applicable for the evaluation of the tree's lateral response as well as the tree stability subjected to lateral loads.

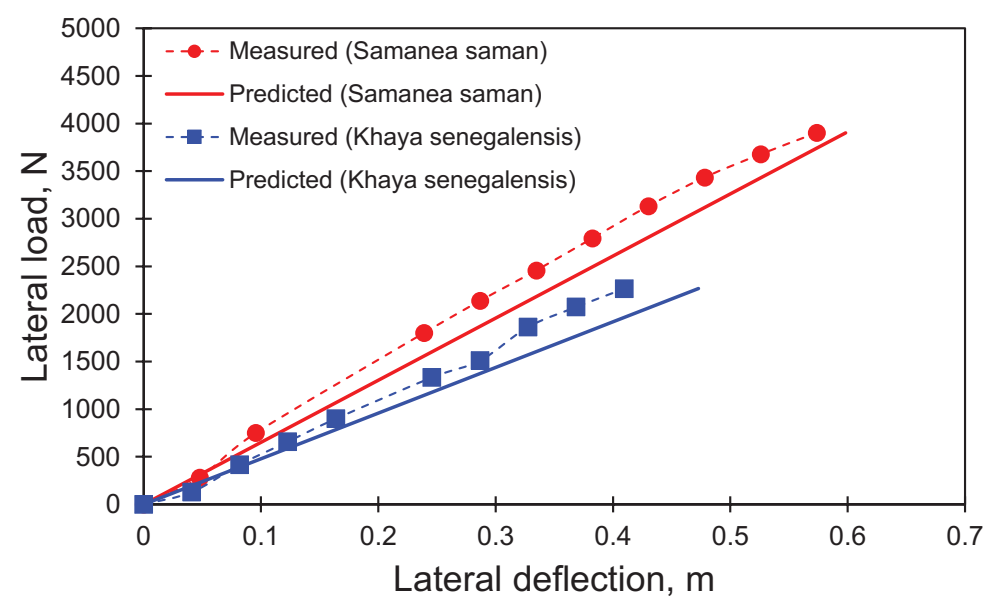

Fig. 7. Comparison between measured and predicted load-deflection curves. 


\subsection{Failure charts for sound trees}

In the computation of data for the tree failure charts, it was assumed that the tree was healthy and made of a single material with elastic modulus $E_{\text {tree }}$ and Poisson's ratio $v_{\text {tree }}$. The fixed tree geometry with a root diameter $B$ of $10 \mathrm{~m}$ and a tree height $m B$ of $20 \mathrm{~m}$ was used. The normalized geometry parameter $n / \beta$ varied from 1.0 to 6.0 . These values and spacing were chosen to acquire detailed tree geometries. The range of parameters adopted for 3D numerical simulations of sound trees was tabulated in Table 7. Note that the lateral behavior of sound trees is affected by the elastic modulus of soils (Kim et al., 2020). In this study, the effects of soil properties on tree stability are ignored to focus on the controlling parameters such as tree geometries and the presence of decay.

For all combinations in the range of tree geometries chosen, the ultimate state of tree materials beyond the equivalent stresses of 30-40 MPa was determined. The lateral load was applied in a gradual step. The analysis stopped when the lateral load reached a $60 \mathrm{kN}$ and/or severe deformation occurred in the model. This limit depends on the failure criterion and the strength parameters.

Table 7 Ranges of parameters adopted for 3D numerical simulations of sound trees.

\begin{tabular}{ll}
\hline Parameter & Value or Range \\
\hline Normalized geometry ratio, $n / \beta$ & $1,2,3,4,5,6$ \\
Trunk height, $m B$ & $20 \mathrm{~m}$ \\
Root diameter, $B$ & $10 \mathrm{~m}$ \\
Trunk diameter, $n B$ & $0.70-2.20 \mathrm{~m}$ with respect to $n / \beta$ \\
Root thickness, $\beta B$ & $0.12-2.20 \mathrm{~m}$ with respect to $n / \beta$ \\
Maximum lateral load & $60 \mathrm{kN}$ \\
\hline
\end{tabular}

Fig. 8 shows a tree failure chart indicating the relationship between the equivalent stress ratio $\sigma_{t} / \sigma_{r}$ and the normalized geometry ratio $n / \beta$, where $\sigma_{t}$ and $\sigma_{r}$ are the maximum equivalent stresses in the trunk and root domains, respectively. The failure chart indicated that the $\sigma_{t} / \sigma_{r}$ ratio decreased gradually with increases in the $n / \beta$ ratio. The physical meaning of the $n / \beta$ ratio refers to the relative dimension between the trunk and root. The higher $n / \beta$ ratio represents the larger diameter of the trunk, resulting in the higher resistance capacity in the trunk from the lateral load. In addition, the distribution of the $\sigma_{t} / \sigma_{r}$ ratio with respect to different tree geometries based on the $n / \beta$ ratio showed a wide range when the $n / \beta$ ratio became smaller. It is due to the fact that developing equivalent stresses in a trunk is influenced by trunk diameters when the root thickness is strong enough to support 
lateral load transferred from the trunk.

For a given value of the $n / \beta$ ratio, tree failure depended on the $\sigma_{t} / \sigma_{r}$ ratio that provides possible notification whether a trunk is likely to fail or root is likely to fail. When the $\sigma_{t} / \sigma_{r}$ ratio is greater than 1.0, and the trunk is prone to failure due to high stress concentration. On the other hand, when the $\sigma_{t} / \sigma_{r}$ ratio is smaller than 1.0, and the root is prone to failure.

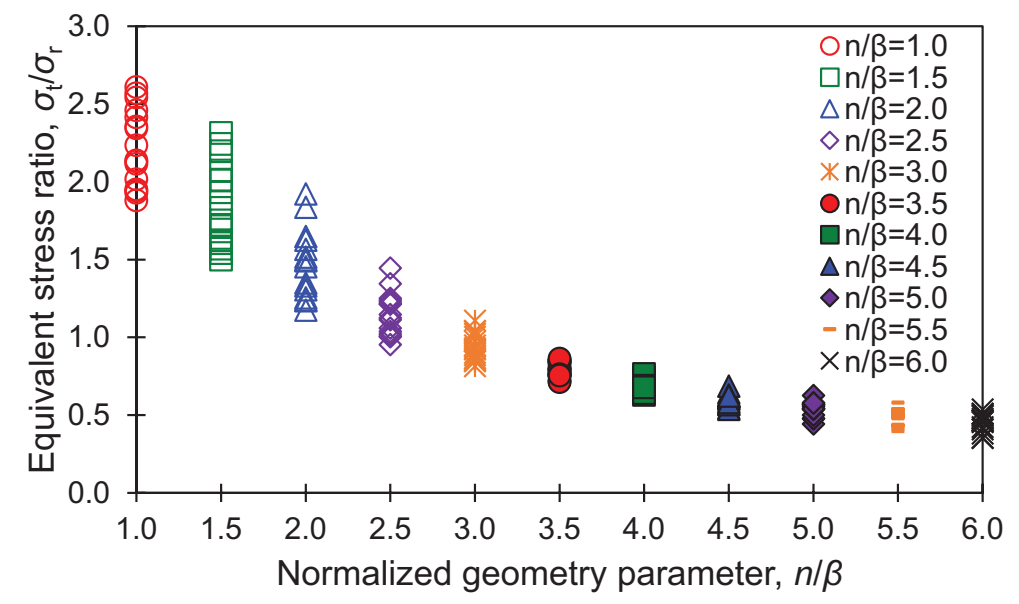

Fig. 8. Failure chart of a sound tree.

\subsection{Behavior of decayed trees under lateral load}

In this section, the lateral behavior of decayed trees and failure loads were investigated using 3D numerical simulations. Fig. 9 shows lateral deflections and equivalent stresses developed in the trunk with respect to the $t / R$ ratios. Fig. 9(a) indicated that the trunk deflection exhibited linear behavior along with the trunk height as assumed and increased with decreases in the $t / R$ ratios. Fig. 9(b) revealed that the equivalent stress increased sharply with decreases in the $t / R$ ratios and the highest equivalent stress developed at the joint between the trunk and the root. When applying the maximum equivalent stress of $30 \mathrm{MPa}$ as a cutoff value that indicates tree failure, the tree with the $t / R$ ratio of 0.1 already failed. For the same applied range of lateral loads, there is a diminishing reduction in the lateral deflections and the equivalent stresses with each increase in the $t / R$ ratio. It is also inferred from the results that sensors to monitor tree's deflection and strains can be attached at the trunk height ranging from 0 to $2 \mathrm{~m}$ because both the lateral deflection and the equivalent stress can be clearly detectable.

Fig. 10 shows a relationship between failure lateral load and root depths with two different $t / R$ ratios. The results show that all roots failed first, and then all trunks failed 
according to the criterion of equivalent stresses. This can be attributed to the decay that has grown from the bottom of the root. Lateral loads acting on the decayed tree with the $t / R$ ratio of 0.1 reached the failure condition earlier than those of $t / R$ ratio of 0.4 . The sound wood could only withstand the lateral load because the decayed wood cannot play a role in transferring lateral loads. It is also found that failure locations in the trunk and root coincided with the locations where the maximum equivalent stress occurred, as shown in Fig. 11.
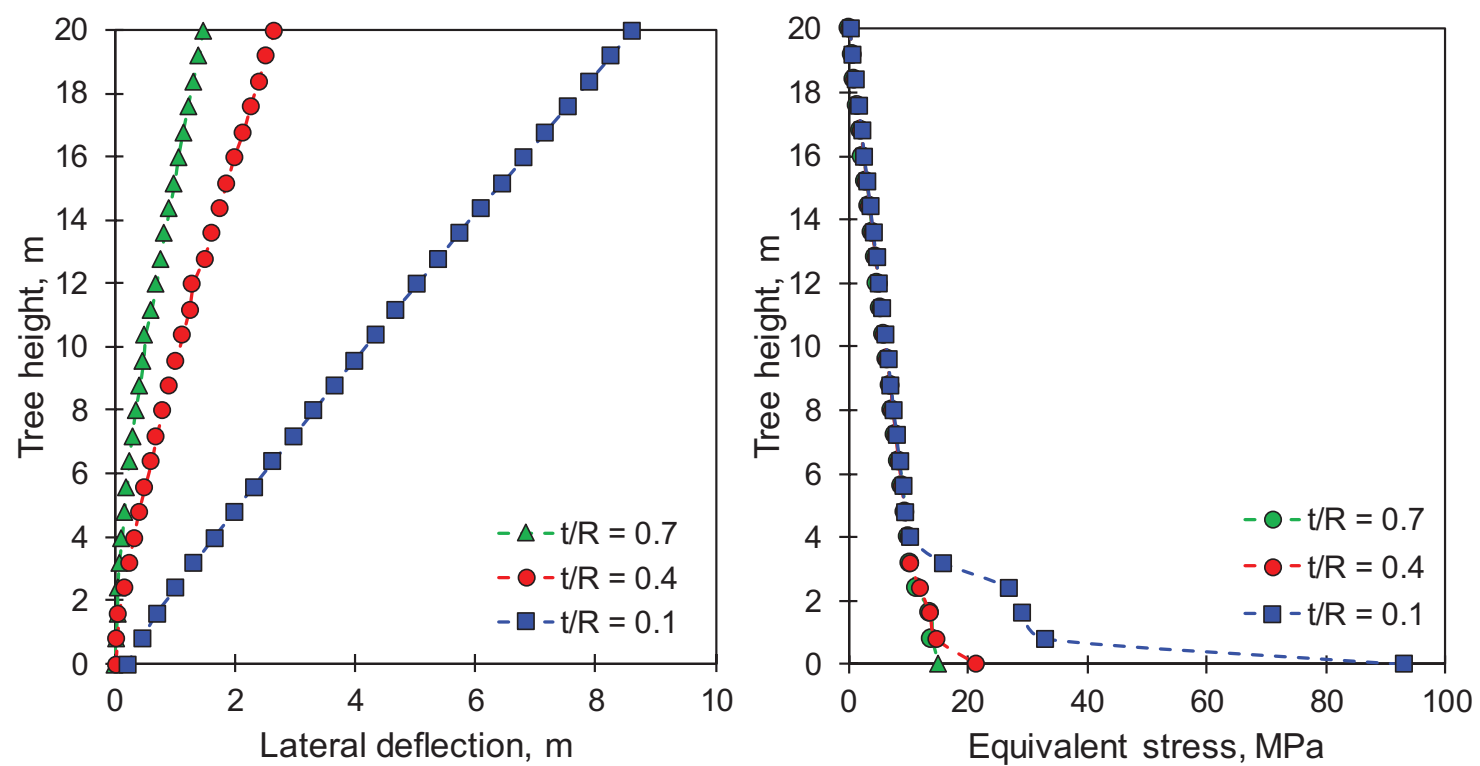

(a) Lateral deflection along the trunk

(b) Developed equivalent stress along the trunk Fig. 9. Lateral behavior and equivalent stress of the decayed tree $(m B=20 \mathrm{~m}, n B=0.8 \mathrm{~m})$.

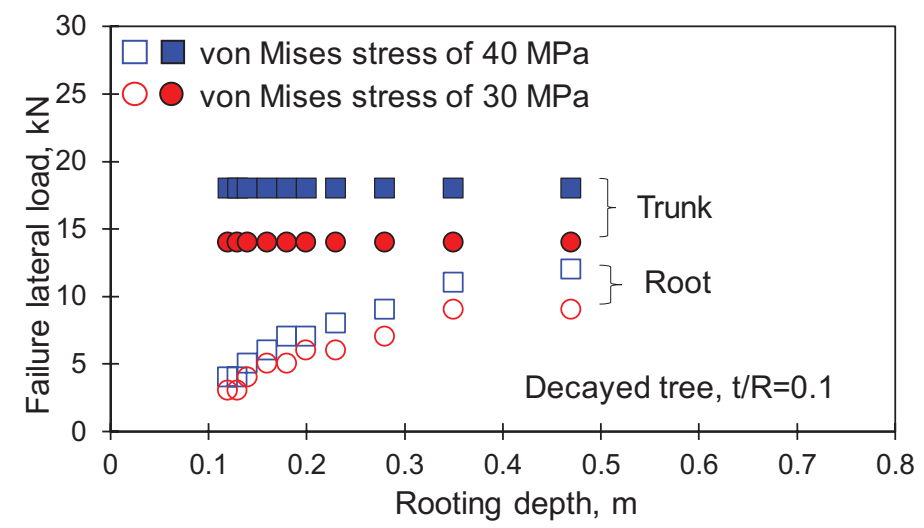

(a) Decayed tree with $t / R$ ratio $=0.1$ 


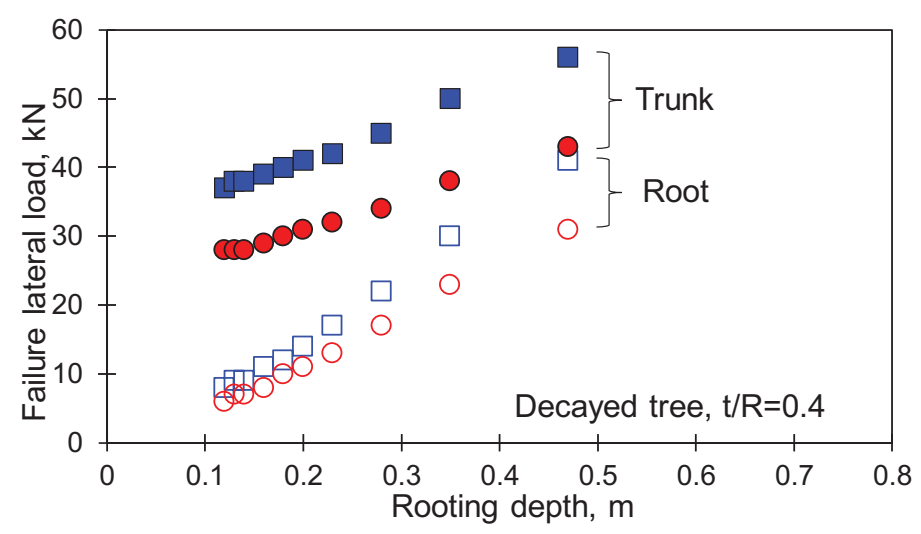

(b) Decayed tree with $t / R$ ratio $=0.4$

Fig. 10. Failure due to lateral load acting on the tree $(m B=20 \mathrm{~m}, n B=0.8 \mathrm{~m})$ based on the criterion of material failure stresses (von Mises stresses).

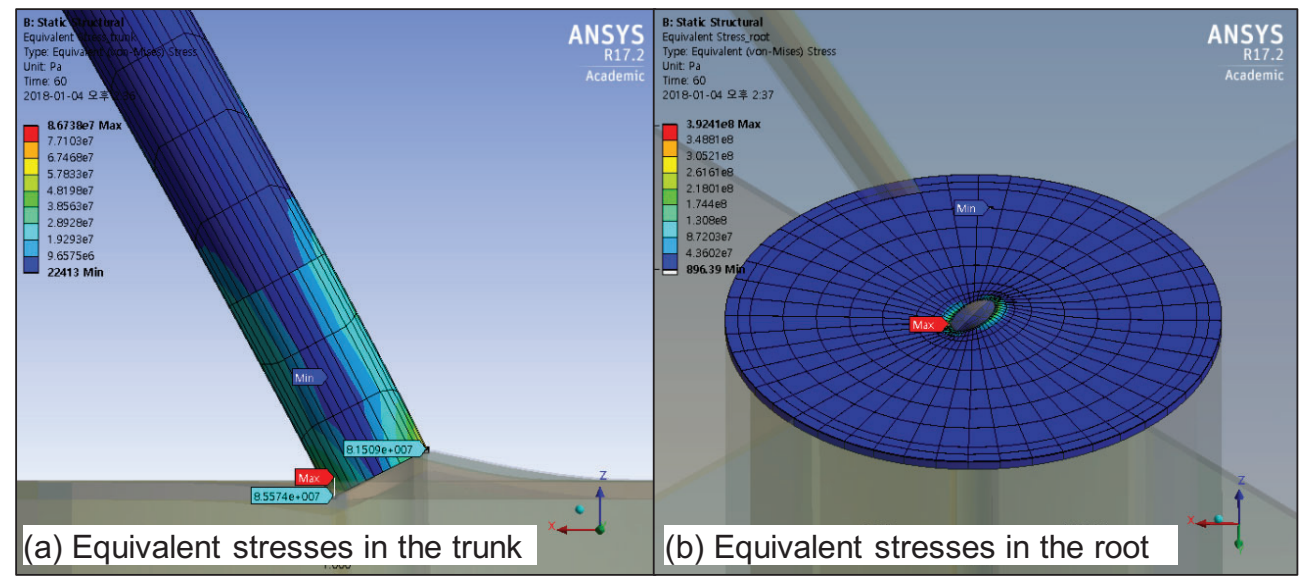

Fig. 11. Contour of equivalent stresses developed in (a) the trunk and (b) the root.

Fig. 12 shows a failure chart of a decayed tree with respect to the $t / R$ ratios. As expected, the $\sigma_{t} / \sigma_{r}$ ratio decreased with increases in the $n / \beta$ ratio, which means that root failure became predominant when the root plate thickness became smaller. However, the $\sigma_{t} / \sigma_{r}$ ratio of the trees with the trunk diameter $n B$ of 0.7 and $1.4 \mathrm{~m}$ started around 1.0 and dropped gradually under 1.0 when the $t / R$ ratio is less than 0.1 and 0.4 , respectively. It can be said that the decayed tree tended to be vulnerable to root failure, and the effect can be significant when the $n / \beta$ became smaller. 


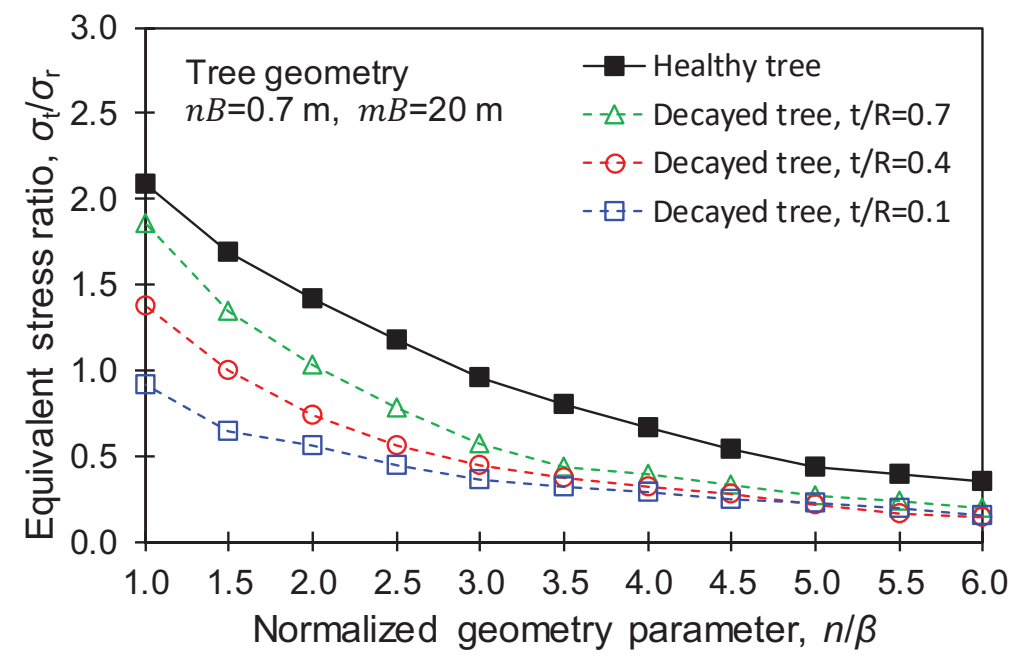

(a) Decayed tree with $n B=0.7 \mathrm{~m}$

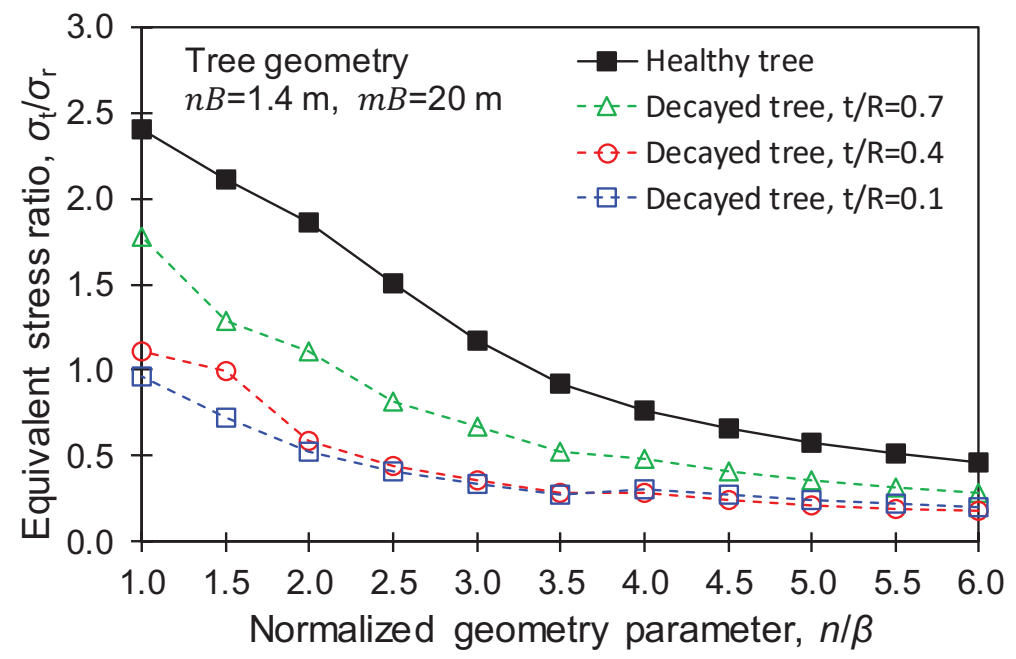

(a) Decayed tree with $n B=1.4 \mathrm{~m}$

Fig. 12. Failure chart of a decayed tree with respect to the $t / R$ ratio.

\subsection{Effects of volume and elastic modulus of decayed wood}

The effects of decay volume and elastic modulus of decayed wood were investigated using 2D numerical simulations. Fig. 13 shows the maximum lateral deflections of the trunk and the maximum equivalent stresses of the root. The maximum lateral deflections gradually increased with growing decay volume in the trunk and root. In particular, the increased rate of the deflection was sharp when the parameter $\omega$ is smaller than 0.01. Similarly, the maximum equivalent stresses increased gradually with increases in the parameter $\kappa$ and then, the equivalent stresses increased sharply when the parameter $\omega$ is smaller than 0.01 . 
In addition to the effect of reduced elastic modulus of decayed wood, severe deflections and high stress concentrations were observed when the parameter $\omega$ became smaller. For a given decayed wood volume, a continuous stress contour near the joint between the trunk and root was obtained when the $\omega$ is 0.5 as shown in Fig. 14(a), while a discontinuous stress contour was obtained when the $\omega$ is 0.05 as shown in Fig. 14(b). This condition is attributed to the deterioration of the elastic modulus of the decayed wood such that it could not transfer the lateral load to adjacent materials. Consequently, stress concentration near the decayed wood occurred, resulting in tree failures.

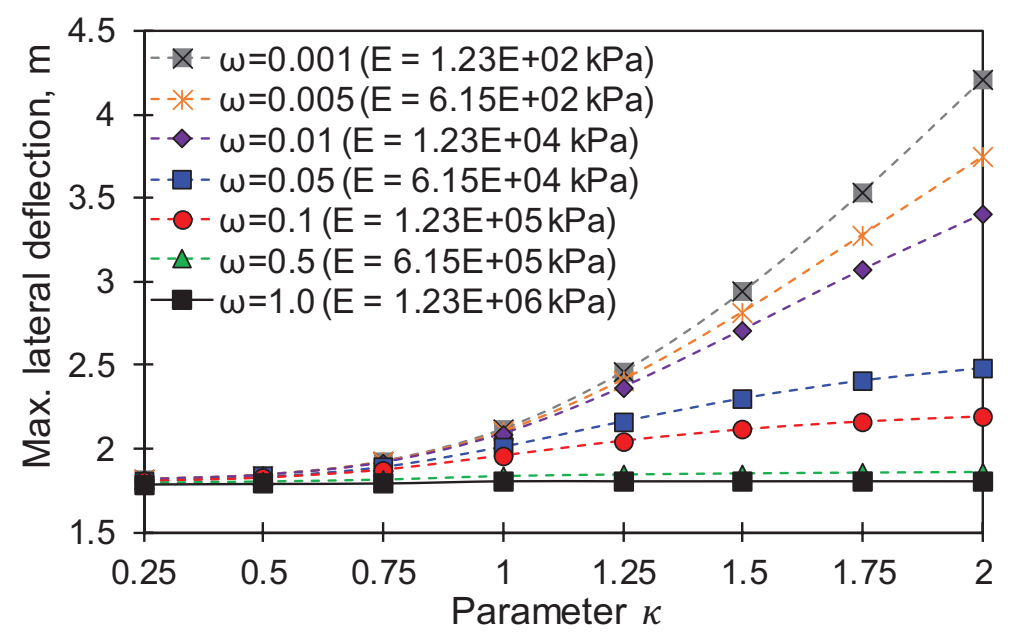

(a) Maximum lateral deflection of the trunk

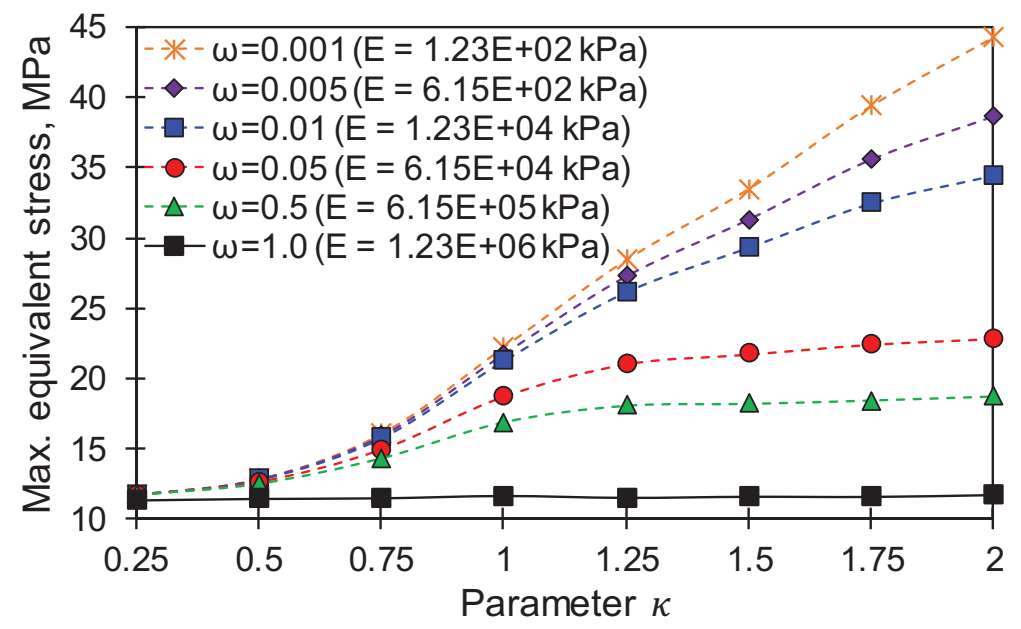

(b) Maximum equivalent stress of the root

Fig. 13. Maximum lateral deflections and equivalent stresses of the tree with various volumes and elastic modulus of decayed wood. 


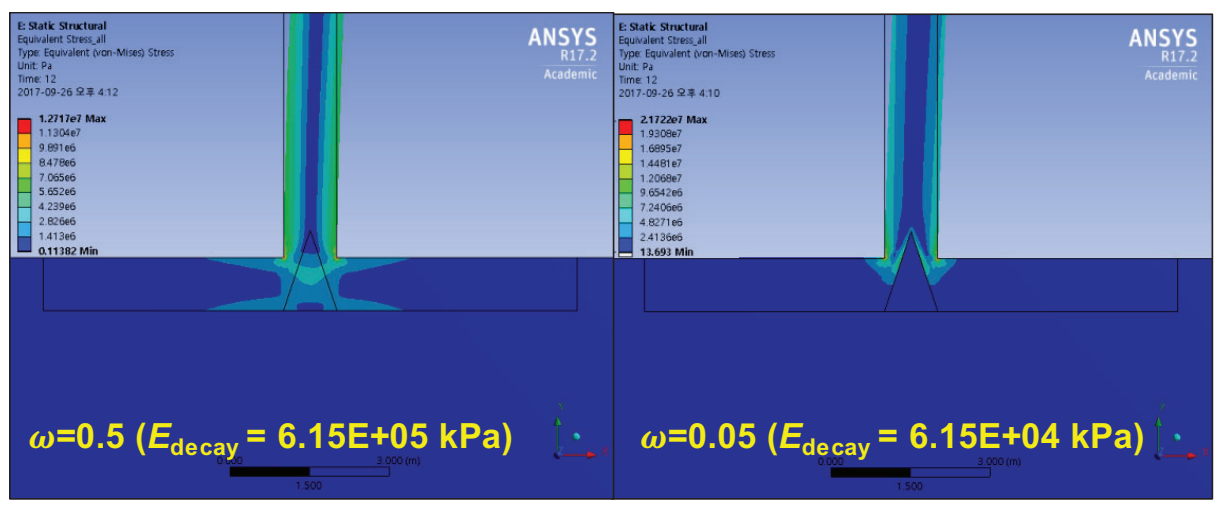

Fig. 14. Contour of equivalent stresses developed on the decayed trunk and root.

\subsection{Limitations in the current study}

In this study, numerical analyses were carried out to develop the failure charts of sound and decayed trees subjected to lateral loads. For reliability of the numerical results, the numerical model of a sound tree was verified against the results of tree pulling tests. However, there are still some limitations in the mechanics affecting the reliability of model validation with decayed trees, causing inaccurate estimation on the failure of decayed trees. However, there is currently little experimental work found in the literature that has been carried out on lateral load response studies for trees with decay. This limitation could be attributed to inherent difficulties in the introduction of defects into healthy standing trees in terms of safety and technical difficulties. The numerical model that shows good mechanical similarities to healthy standing trees (see Fig. 7) provides the logical avenue that allows defects to be introduced and the resulting changes in biomechanical responses can be used as a reference for the load testing of standing trees for the purpose of the detection of defects. Based on the results of the numerical model for the sound tree; therefore, it was assumed that a numerical model for hollow symmetrical decayed trees with $t / R$ ratios should also produce a reasonable result because the modelling processes of the tree and soil, and the application of the lateral load were the same in both cases.

The elastic modulus of the decayed wood was assumed to be arbitrary values reduced from the elastic modulus of the sound wood to qualitatively investigate the effects of decay in the tree's response to lateral loads. Although no experiments have ever been carried out to obtain the value of the elastic modulus of decayed woods, the reduction in the elastic modulus for the decayed wood is the alternative approach to attract the loads to be taken up by the sound 
wood. As mentioned, this is a study of the effects of the different elastic moduli and defect sizes on the biomechanical response of the tree model. Laboratory and field testing to obtain data from real decayed trees could be incorporated in future studies of tree stability.

\section{Conclusions}

The main objective of this study is to develop the numerical models to simulate decayed trees under lateral load. For this work, the 3D numerical modeling was presented and verified against tree pulling tests by taking into account tree-soil interaction. Based on the 3D modeling technique, decayed trees were simulated with the incorporation of $t / R$ ratio concept and reduced elastic modulus for a decayed wood. In addition, to examine the effects of decay's volume and reduced elastic modulus, a simplified 2D numerical simulation was performed. The following conclusions can be drawn from the present study:

1. Based on the analysis results from the tree pulling simulations, a reasonably good agreement of load-deflection relationships was obtained between the numerical analysis results and field tree pulling test results for both Khaya senegalensis and Syzysium grande. Therefore, the numerical model of the trunk-root plate-soil system with the incorporation of the overall stiffness of the tree was an appropriate approach that is applicable for the evaluation of the tree's lateral response as well as the tree stability.

2. A failure chart of a sound tree was proposed based on the results of $3 \mathrm{D}$ numerical simulations to investigate whether the trunk is likely to fail or the root is likely to fail by estimating the equivalent stress ratio $\sigma_{t} / \sigma_{r}$ with respect to the normalized geometry ratio $n / \beta$. When the $\sigma_{t} / \sigma_{r}$ ratio is smaller than 1.0 , the root is prone to failure and vice versa.

3. Severe lateral deflections and equivalent stresses of the decayed tree were observed as compared to the sound tree. There is a diminishing reduction in both the lateral deflections and the equivalent stresses with each increase in the $t / R$ ratio. The lateral load acting on the decayed tree reached failure condition earlier than the sound tree, resulting in root failure. In addition to a failure chart, the $\sigma_{t} / \sigma_{r}$ ratio tended to be downward with respect to the presence of decay as compared to the sound tree. It can then be said that the decayed tree was more vulnerable to root failure. 
4. In addition, the $2 \mathrm{D}$ numerical simulations have shown that lateral behavior and stability of decayed trees were strongly dependent on the decay's volume and the reduction in elastic modulus of the decayed wood. Lateral deflections and equivalent stresses of trees increased with increasing decay volume and decreasing elastic modulus of decayed wood. A discontinuous contour was observed in the decayed wood that could not transfer the lateral load to adjacent materials. Consequently, severe deflections and high stress concentrations occurred at joints, resulting in tree failures.

\section{List of Notations}

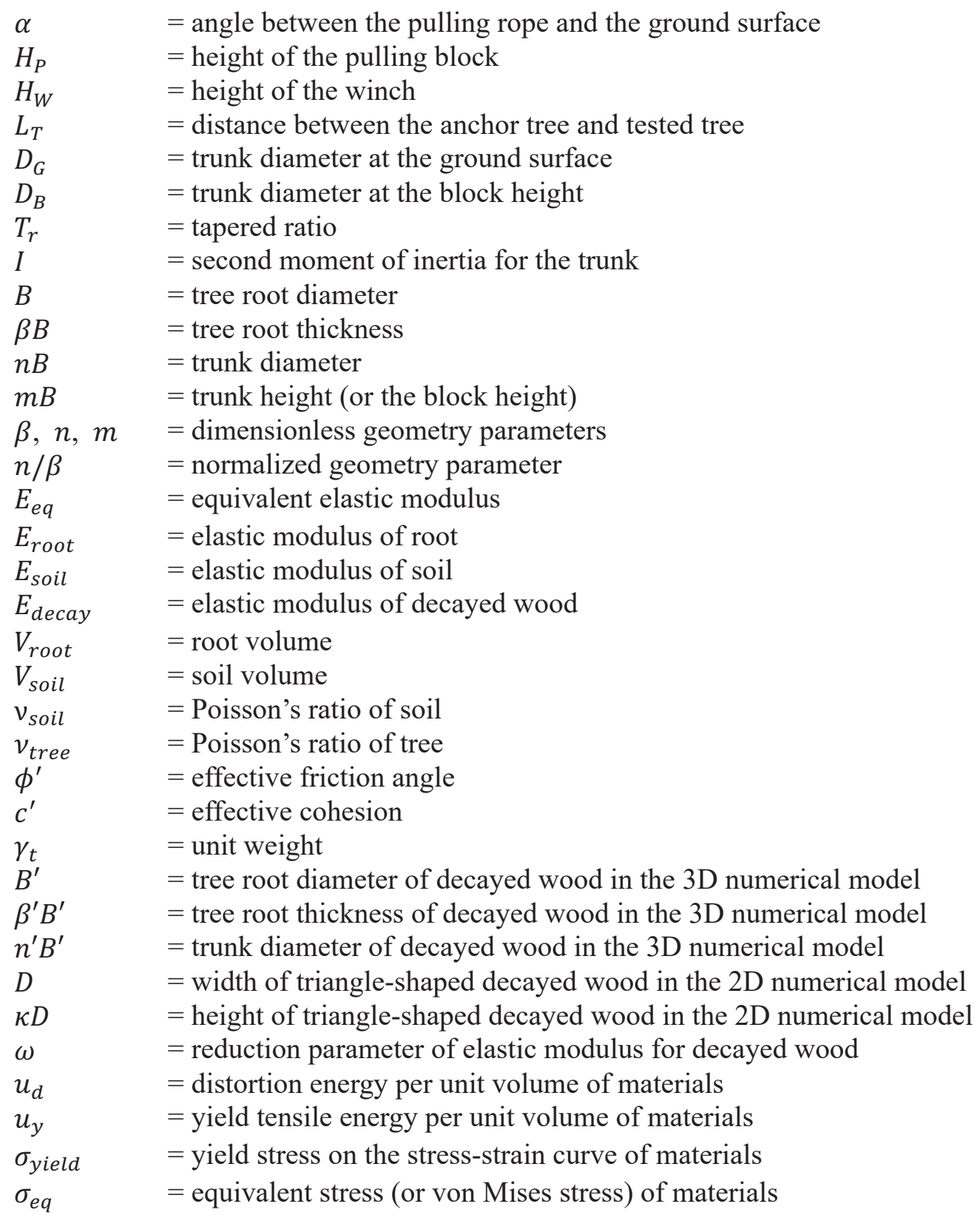


$\sigma_{t}$ and $\sigma_{r}=$ maximum equivalent stresses in trunk and root, respectively

$\sigma_{t} / \sigma_{r} \quad=$ equivalent stress ratio

\section{References}

ANSYS, 2011. User's Manual 14. ANSYS Inc., Canonsburg, PA., USA.

Arciniegas, A., Prieto, F., Brancheriau, L., Lasaygues, P., 2014. Literature review of acoustic and ultrasound tomography in standing trees. Trees Struct. Fun. 28, 1559-1567.

Bartens, J., Wiseman, P.E., Smiley, E.T., 2010. Stability of landscape trees in engineered and conventional urban soil mixes. Urban For. Urban Green. 9, 333-338.

Boresi, A.P., Schmidt, R.J., 2002. Advanced Mechanics of Materials, 6th edition. John Wiley \& Sons.

Chow, W.T., Roth, M., 2006. Temporal dynamics of the urban heat island of Singapore. Int. J. Climatol. 26 (15), 2243-2260.

Coutts M.P., 1983 Root architecture and tree stability. Plant Soil 71 (1-3), 171-188.

Dunster, J.A., Smiley, E.T., Matheny, N., Lilly, S., 2013. Tree risk assessment manual. International Society of Arboriculture. Champaign, Illinois, U.S.

Elie, J.G., Ruel, J.C., 2005. Windthrow hazard modeling in boreal forests of black spruce and jack pine. Can. J. Forest Res. 35, 2655-2663.

Gilman, E.F., Masters, F.J., 2010. Effect of tree size, root pruning, and production method on root growth and lateral stability of Quercus virginiana. Arboric. Urban For. 36 (6), 281291.

Harnas, F.R., Rahardjo, H., Leong, E.C., Tan, P.Y., Ow, L.F., 2015. Stability of containerized urban street trees. Landscape Ecol. Eng. 12 (1), 13-24.

James, K.R., Haritos, N., Ades, P.K., 2006. Mechanical stability of trees under dynamic loads. Am. J. Bot. 93 (10), 1361-1369.

Jorgensen, A., Anthopoulou, A., 2007. Enjoyment and fear in urban woodlands-Does age make a difference? Urban For. Urban Green. 6, 267-278.

Kane, B., Clouston, P., 2008. Tree pulling tests of large shade trees in the genus Acer. Arboric. Urban For. 34 (2), 101-109.

Kane, B., Ryan, D., Bloniarz, D.V., 2001. Comparing formulae that assess strength loss due to decay in trees. Arboric. J. 27 (2), 78-87.

Khalilnejad, A., Ali, F.H., Hashim, R., Osman, N., 2013. Finite-element simulation for contribution of matric suction and friction angle to stress distribution during pullingout process. Int. J. Rock Mech. Min. Sci. 13 (5), 527-532. 
Kim. Y., Rahardjo, H., Lee, D.T.T., 2020. Stability analysis of laterally loaded trees based on tree-root-soil interaction. Urban For. Urban Green. 49, 126639.

Koizumi, A., Motoyama, J., Sawata, K., Sasaki, Y., Hirai, T., 2010. Evaluation of drag coefficients of poplar-tree crowns by a field test method. Japan Wood Res. Soc. 56, 189193.

Lee, D.T.T., 2016. Effect of Rainfall on Tree Stability. Ph.D. Thesis. Nanyang Technological Univ., Singapore.

Li, Y, Rahardjo, H., Irvine, K.N., Law, A.W.K., (2018) CFD Analyses of the Wind Drags on Khaya Senegalensis and Eugenia Grandis. Urban For. Urban Green., 34, $29-43$.

Li, Y., Rahardjo, H., Irvine, K.N., (2019). Effect of Weather Conditions on Leans of One Eugenia Grandis Tree in Singapore. Urban For. Urban Green. 43, 126375.

Lonsdale, D., 2007. Current issues in arboricultural risk assessment and management. Arboric. J. 30 (2), 163-174.

Miesbauer, J.W., Gilman, E.F., Masters, F.J., Nitesh, S., 2014. Impact of branch reorientation on breaking stress in Liriodendron tulipifera L. Urban For. Urban Green. 13 (3), 526-533

Moore, J.R., 2000. Differences in maximum resistive bending moments of Pinus radiata trees grown on a range of soil types. Forest Ecol. Manag. 135, 63-71.

Ow, L.F., Harnas, F.R., Indrawan, I.G.B., Sahadewa, A., Sim, E.K., Rahardjo, H., Leong, E.C., Fong, Y.K., Tan, P.Y., 2010. Tree-pulling experiment: an analysis into the mechanical stability of rain trees. Trees Struct. Fun. 24, 1007-1015.

Peltola, H., Kellomaki, S., Hassinen, A., Granader, M., 2000. Mechanical stability of Scots pine, Norway spruce, and birch: an analysis of tree-pulling experiments in Finland. Forest Ecol. Manag. 135, 143-153.

Rahardjo, H., Harnas, F.R., Indrawan, I.G.B., Leong, E.C., Tan, P.Y., Fong, Y.K., Ow, L.F., 2014. Understanding the stability of Samanea saman trees through tree pulling, analytical calculations and numerical models. Urban For. Urban Green. 13, 533-364.

Rahardjo, H., Harnas, F.R., Leong, E.C., Tan, P.Y., Fong, Y.K., Sim, E.K., 2009. Tree stability in an improved soil to withstand wind loading. Urban For. Urban Green. 8 (4), 237-247.

Rahardjo, H., Melinda, F., Leong, E.C., Rezaur, R.B., 2011. Stiffness of a compacted residual soil. Eng. Geol. 120, 60-67.

Smiley, E.T., 2008. Root pruning and stability of young willow oak. Arboric. Urban For. 34 (2), $123-128$.

Soltis, L.A., 1999. Structural analysis equations, Wood Handbook: Wood as an Engineering Material. General Technical Report FPL-GTR-113. USDA, Forest Products Laboratory, Madison, WI, pp. 8-1-8-12.

Terho, M. 2009. An assessment of decay among urban Tilia, Betula, and Acer trees felled as hazardous. Urban For. Urban Green. 8, 77-85. 
Tresca, H., 1864. Mémoire sur l'écoulement des corps solides soumis à de fortes pressions. C.R. Acad. Sci. Paris, 59, 754.

von Mises, R., 1913. Mechanik der festen Körper im plastisch deformablen Zustand. Göttin. Nachr. Math. Phys. 1, 582-592.

Wang, X., Allison B.R., 2008. Decay detection in red oak trees using a combination of visual inspection, acoustic testing, and resistance microdrilling. Arboric. Urban For. 34 (1), 1-4. 